\title{
CURRÍCULO, GÊNERO E SEXUALIDADE: QUESTÕES INDISPENSÁVEIS À FORMAÇÃO DOCENTE
}

Márcio Porciúncula FERREIRA ${ }^{1}$

Universidade Federal de Pelotas/UFEPEL porciuncula.marcio@gmail.com

Resumo: O presente trabalho trata das questões de currículo, gênero e sexualidade como problema. Desde então, objetiva pensar algumas práticas educativas na produção de desigualdades sexuais e de gênero, em suas articulações com a Educação. Recebe atenção o modo como os sujeitos, em relações sociais atravessadas por diferentes discursos, representações e práticas pedagógicas, vão construindo suas identidades, arranjando e desarranjando suas posições e formas de viver e estar no mundo. Também, trata de mostrar alguns mecanismos, instituições e artefatos tão cotidianos, rotineiros e comuns, formadores de Verdade e Moral, dos quais todos fazemos parte. A tarefa mais urgente é desconfiar do que é tomado como "natural" e "normal". Possibilitar uma prática ambiental afirmativa, fazendo educação potencializando os vários tipos de vida que encontramos pela Terra, preservando os diferentes desejos, é o que nos interessa.

Palavras-chave: Currículo. Gênero. Sexualidade. Sexismo.

Abstract: The present work deals with issues on curriculum, gender and sexuality treating them as a problem. Since then, it aims on thinking some educational practices in the production of sexual and gender inequalities, in its relations with Education. Receives attention the way subjects, in social relations trespassed by different speeches, representations and teaching methods, build

1 Professor do curso de Pedagogia UAB/UFPel. Mestre em Educação pela Universidade Federal do Rio Grande do Sul. 
their identities, arranging and deranging their positions and way of living and being in the world. Also, it shows some mechanisms, institutions and artifacts, so common, daily and present in our routines, shapers of Truth and Morals, of which all take part. The most urgent task is to question what is taken as "natural" and "normal". To enable an affirmative environmental practice, making education, enhancing the several lifestyles we find in Earth, preserving different desires, is our interest.

Keywords: Curriculum. Gender. Sexuality. Sexism.

\section{Introdução}

$\mathrm{Na}$ minha monografia do curso de graduação em Pedagogia, trabalhei com a ideia de gênero e sexualidade como experiência dentro do campo da educação e do currículo. Textos fundamentais da literatura educacional pós-crítica me levaram a um diferente questionamento do fazer pedagógico. Dessa maneira, o currículo e as temáticas de gênero e sexualidade surgiram como possibilidades de delinear alguns caminhos para responder às novas inquietações e curiosidades que me apareciam desde o início da graduação.

Em muitas obras e textos, tais como "Documentos de Identidade: uma introdução às teorias do currículo", de Tomaz Tadeu da Silva, O corpo educado: pedagogias da sexualidade, de Guacira Lopes Louro e Escola, currículo e produção de diferenças e desigualdades de gênero, de Dagmar Meyer, as concepções de gênero e sexualidade aparecem ligadas à questão do currículo. Se falo desses autores, é para marcar que as ideias com as quais trabalhei na minha pesquisa foram também desenvolvidas por eles em diversos textos. No entanto, outro pensador - Michel Foucault - foi o grande motivador desses pesquisadores. Com Foucault se abre um mundo novo para pensar a Educação.

O corte que pretendo fazer aqui é sobre a leitura que faço dessas questões de gênero e sexualidade, implicadas no campo da educação, do currículo e da pedagogia. 


\section{Fazendo gênero}

Ao longo das últimas décadas, predominantemente a partir dos anos 60, tem-se assistido a movimentos crescentes a respeito dos rígidos e inflexíveis padrões de valores masculinos e femininos, vigentes nas diferentes sociedades. Agora, as barreiras que separam mulheres e homens em seus respectivos papéis sociais parecem ameaçadas de fragmentação. Mas, apesar da aparente superação desse problema, pode-se perceber ainda profundas desigualdades nas relações de gênero e sexualidade no mundo inteiro.

A partir daí, senti a necessidade de tratar neste texto de algumas noções sobre gênero e sexualidade contribuindo para a desconstrução, debate e polêmica que giram em torno dessa área do conhecimento pedagógico.

\section{Algumas noções sobre gênero}

Segundo Scott (1990), gênero parece primeiro ter feito sua aparição entre as feministas americanas que queriam insistir sobre o caráter fundamentalmente social das distinções fundadas sobre o sexo. A palavra indicava uma rejeição ao determinismo biológico implícito no uso dos termos como 'sexo' ou 'diferença sexual'. "O gênero enfatizava igualmente o espaço relacional das definições normativas da feminilidade" (ibid., p. 5). Aquelas que estavam preocupadas pelo fato de a produção de estudos femininos se centrar sobre as mulheres de maneira demasiado estreita e separada utilizaram o termo 'gênero' para introduzir uma noção nesse vocabulário de análise. As pesquisadoras feministas assinalaram muito cedo que o estudo das mulheres não acrescentaria somente novos temas, mas que ele iria igualmente impor um reexame crítico das premissas e dos critérios do trabalho científico existente. "O interesse pelas categorias de raça e gênero assinalava, primeiramente, o engajamento do pesquisador numa história que incluía os discursos das oprimidas e numa análise do sentido e da natureza de sua opressão" (SCOTT, 1990, p. 6).

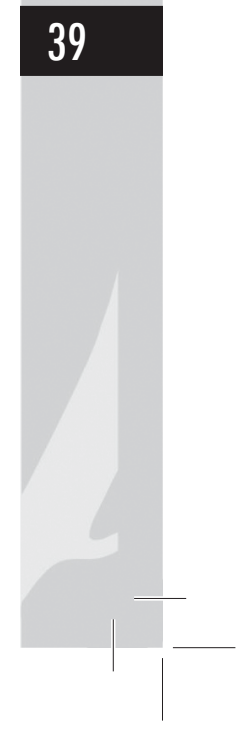


Scott (1990) afirma ainda que, na sua utilização mais simples, 'gênero' é sinônimo de 'mulheres'. Os livros e artigos de todos os tipos que tinham como assunto a história das mulheres substituíram, nos últimos anos, nos seus títulos o termo 'mulher' por 'gênero'. A emergência desse conceito é examinada na perspectiva da história do movimento feminista contemporâneo uma vez que seus sentidos teóricos e políticos foram sendo construídos nesse processo. De acordo com Louro (1997), embora no Brasil o conceito comece a aparecer nos textos acadêmicos ao final dos anos 1980, pode-se resgatar a presença da importante distinção entre gênero (gender) e sexo (sex) no discurso de autoras feministas anglo-saxãs já na década de 1970 e início dos anos 1980. Essa distinção permite problematizar o determinismo biológico implícito no termo 'sexo' e enfatizar o caráter de construção social do que é feminino ou masculino num determinado espaço e tempo. O deslocamento da ênfase, contudo, não pretende "negar que o gênero se constitui com ou sobre corpos sexuados", mas acentuar "a construção social e histórica produzida sobre as características biológicas" (LOURO, 1997, p. 22). Esse deslocamento não resulta apenas de uma nova focalização teórica, mas da intenção política de recolocar o debate sobre as relações de desigualdade entre homens e mulheres no campo social, espaço de construção e reprodução dessas relações.

Segundo Meyer:

O conceito de gênero também não se refere mais ao estudo da mulher, ele é um conceito que procura enfatizar a construção relacional e a organização social das diferenças entre os sexos, desestabilizando dessa forma o determinismo biológico e econômico vigente até então, em algumas das teorizações anteriores. (2001, p. 32)

De acordo com Meyer (2001), o que é apresentado como feminino, nas sociedades ocidentais, toma o masculino como referência. A mulher é apresentada como o oposto do homem, só 
que essa não é uma simples oposição hierarquizada em que um dos termos é socialmente menos valorizado que o outro. Gênero, então, enfatiza a construção relacional do sexo e a organização social dessa construção, entendendo que ela é uma construção histórica e que precisa ser entendida a partir de sua articulação com outras categorias sociais.

\section{Gênero e identidade}

Compreendendo o gênero como constituinte da identidade dos sujeitos, Louro (1997, p. 24) opera com uma concepção de "identidades plurais, múltiplas; identidades que se transformam, que não são fixas ou permanentes, que podem, até mesmo, ser contraditórias". Essa concepção acentua a ideia de que os sujeitos não são unos e homogêneos e que, portanto, o entendimento das relações de desigualdade requer a análise da articulação de gênero a outras dimensões sociais, tais como étnicas, sexuais e de classe, entre outras. Além disso, o caráter de construção social de tais dimensões não permite pensar que há um momento na nossa vida em que a identidade esteja acabada, definitivamente pronta.

Então, se mulheres e homens se constroem num processo de relação e no interior de uma sociedade, os conceitos de gênero, segundo Louro (1995), também são plurais. Esses sujeitos são distintos histórica e socialmente: ser homem hoje é diferente de ter sido homem no início do século, assim como ser hoje, mulher de classe média, branca e brasileira é diferente de ser hoje, mulher, pobre, negra e afrodescendente. Um outro desdobramento importante desse conceito é a proposição de afastar-se das análises que repousam sobre uma ideia reduzida de papéis ou funções de mulher e de homem, o que nos leva a pensar que "as próprias instituições, os símbolos, as normas, as leis de uma sociedade são constituídas pelas representações de feminino e masculino e expressam e reproduzem essas representações" (MEYER, 2001, p. 33).

É importante então desconstruirmos a oposição masculino-feminino, para que se possa avançar na compreensão 
das relações de gênero. Feministas argumentam que desconstruir significa problematizar a oposição entre masculino e feminino assim como sua unidade interna, dizendo que o polo masculino contém também o feminino, de um modo muitas vezes reprimido e disfarçado, assim como o feminino contém o masculino, e que cada um dos gêneros não é uno, mas plural, fraturado e dividido.

\section{Gênero e Educação}

Ao pensarmos em Educação, o tema facilmente nos remete a duas instituições sociais e ideológicas que têm um papel preponderante sobre a vida das pessoas: a família e a escola. É na família que começam a ser vividas as primeiras experiências que possibilitarão o desenvolvimento de comportamentos sociais em cada um/a de nós, iniciando assim a construção de nossas identidades sociais, nos constituindo como sujeitos específicos e genéricos. Nela começam também a ser demarcadas as grandes diferenças entre meninos e meninas.

Os homens e as mulheres nas suas funções de pais e mães entendem que todas as pessoas precisam se construir como homens e mulheres de acordo com as regras do 'manual' que a sociedade na qual estão inseridos/as admite, aceita e estipula como o 'certo'. Nesse caso, é preciso que a família, em seu tempo, aponte comportamentos e atitudes ditos 'corretos', para a 'boa formação' do ser homem e do ser mulher. Com isso, Meyer afirma que:

O conceito de gênero indica mais ou menos o seguinte: nós aprendemos a ser homens e mulheres desde o momento em que nascemos até o dia em que morremos e essa aprendizagem se processa em diversas instituições sociais, a começar pela família, passando pela escola, pela mídia, pelo grupo de amigos, pelo trabalho etc. (2001, p. 32)

Hoje, os preconceitos relativos à educação mais adequada para a mulher já não se manifestam de forma tão visível como no passado. As formas de discriminação se tornam sutis, os 
preconceitos são revelados, sobretudo pela participação seletiva da mulher no sistema educativo e não por sua ausência nos meios de ensino. No entanto, através de diferentes maneiras, a escola transmite padrões de comportamento sexual culturalmente estereotipados, reforçando assim a desigualdade social entre os gêneros. Segundo a feminista Guacira Louro,

Diferenças, distinções, desigualdades... A escola entende disso. Na verdade a escola produz isso. Desde seus inícios, a instituição escolar exerceu uma ação distintiva. Ela se incumbiu de separar os sujeitos - tornando aqueles que nela entravam distintos dos outros, os que a ela não tinham acesso. Ela dividiu também, internamente, os que lá estavam, através de múltiplos mecanismos de classificação, ordenamento, hierarquização. A escola que nos foi legada pela sociedade ocidental moderna começou por separar adultos de crianças, católicos de protestantes. Ela também se fez diferente para os ricos e para os pobres e ela imediatamente separou os meninos das meninas. (1997, p. 57)

Ainda hoje, as escolas continuam desempenhando vários papéis relacionados com a diferença de gênero, reproduzindo as desigualdades. Assim, quando tentam transmitir conhecimentos às estudantes, as escolas seguem as regras da divisão sexual do trabalho na sociedade, preparando as mulheres para posições semelhantes àquelas de suas mães e de outros membros de seu sexo. As mulheres são identificadas com a arena privada da casa e das relações pessoais e os homens, com o espaço público, da produção e da política. Pode-se perceber claramente essa separação até mesmo nas atividades dentro da escola, nos exercícios de cada disciplina considerados 'naturalmente' masculinos ou femininos ou, inicialmente, até mesmo com as questões de acesso à escola. Tomaz Tadeu da Silva diz que:

o nível de educação das mulheres, em muitos países, sobretudo naqueles situados na periferia do 


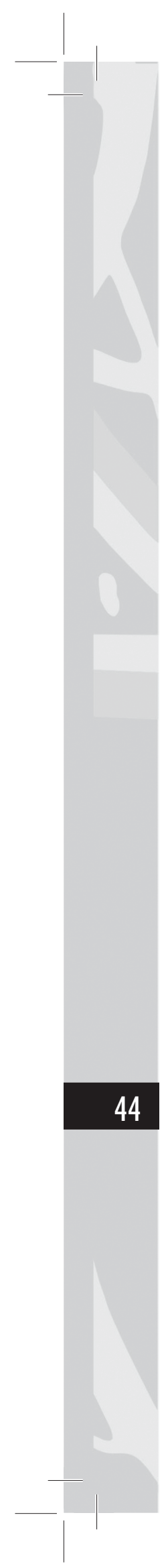

capitalismo, era visivelmente mais baixo do que o dos homens, refletindo seu acesso desigual às instituições educacionais. Mesmo naqueles países em que o acesso era aparentemente igualitário, havia desigualdades internas de acesso aos recursos educacionais: os currículos eram desigualmente divididos por gênero. (1999, p. 92)

É o poder que está incutido no currículo que delimita essa separação. Silva (1996, p. 168) afirma que o "poder está inscrito no currículo". A seleção dos conhecimentos é reveladora das divisões sociais e da legitimação de alguns grupos em detrimento dos outros. Para esse autor, o poder é precisamente "aquilo que divide o currículo - que diz o que é conhecimento e o que não é - e aquilo que essa divisão divide - que estabelece desigualdades entre indivíduos e grupos sociais".

Assim, a escola que adota ou assume essa visão de currículo continua sendo a reprodutora e produtora de instituições e desigualdades sociais, atualmente de forma mais velada. A escola delimita espaços. Servindo-se de símbolos e códigos, ela determina o que cada um pode ou não pode fazer, ela separa e institui cada sujeito. Informa o 'lugar' dos pequenos e dos grandes, dos meninos e das meninas. Através dos seus modelos, aponta aqueles/as que deverão ser copiados/as e permite também que os sujeitos se reconheçam (ou não) nesses modelos. "Sob novas formas, a escola continua imprimindo sua 'marca distintiva' sobre os sujeitos. Através de múltiplos e discretos mecanismos, escolarizam-se e distinguem-se os corpos e as mentes" (LOURO, 1997, p. 62).

Com isso, pode-se perceber que o currículo existente ainda continua claramente masculino ou pode-se pensar que o currículo 'dito' masculino, do modo como se apresenta é também machista, uma vez que anula o potencial feminino para as 'coisas' do mundo, colocando a mulher submissa ao homem diante das potencialidades de ambos.

Para Silva (1999), o currículo “é a expressão da cosmovisão masculina”. O autor suspeita, sobretudo, do chamado currículo 
oficial que valoriza e põe em evidência características que refletem os conhecimentos e as experiências ditas masculinas: o domínio e o controle, a racionalidade e a lógica, a ciência e a técnica, o individualismo e a competição. São precisamente essas características que conferem ao currículo seu caráter masculino e machista. Para o autor,

Esse falocentrismo do currículo tem implicações não apenas para a formação da identidade feminina, como também é evidente para a produção da identidade masculina (...). Um currículo masculinamente organizado contribui, centralmente, para reproduzir e reforçar o dominio masculino sobre as mulheres. (SILVA, 1995, p. 189)

Entretanto, além do conhecimento corporificado no currículo ser machista, podemos verificar que diferentes aprendizagens sobre gênero são proporcionadas aos/às estudantes. Diferentes papéis e características são atribuídas a meninos e meninas, o que pode estar contribuindo para instituir 'verdades' sobre os diferentes sexos. Esse currículo partido acaba por levar a um olhar dividido para meninos e meninas. Por esse olhar dividido, somos levados, por exemplo, a recompensar um menino e a corrigir uma menina por um comportamento semelhante. São por essas atitudes que somos levados a explicar ou justificar de maneiras desiguais seus desempenhos. Assim, a escola não apenas reproduz ou reflete as concepções de gênero e sexualidade que circulam na sociedade, mas ela própria as produz. Isso leva ao entendimento de que a proposta objetiva e explícita da escola é a constituição de sujeitos masculinos e femininos heterossexuais. Os discursos e as práticas escolares vinculam gênero e sexualidade no sentido da heterossexualidade, segundo os padrões hegemônicos e hipócritas da sociedade de que a escola faz parte.

A construção de gênero é realizada nas múltiplas instâncias sociais, nas diferentes práticas, espaços e instituições, através dos símbolos, normas e doutrinas, através das intricadas 


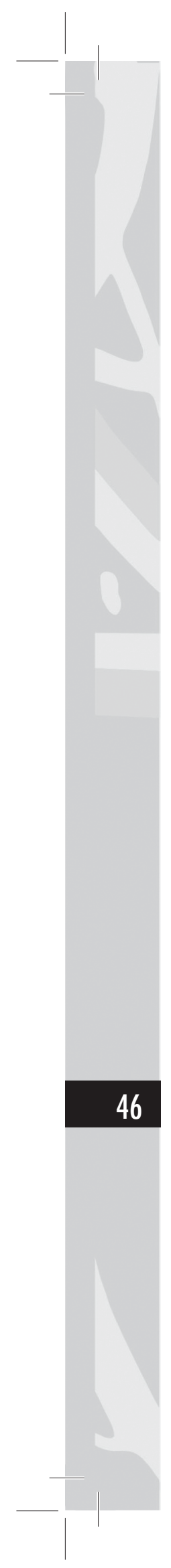

redes de relações entre os sujeitos. Como foi visto anteriormente, a escola, "ao longo de sua história e na configuração atual, também tem criado e recriado formas de produção de sujeitos 'generificados"' (LOURO, 1995, p. 174). É então, no cotidiano comum dos pequenos e rotineiros eventos que a escola assim como as outras instituições sociais - 'fabrica' homens e mulheres. É claro que esse fazer diário na escola não é autônomo; ele está, evidentemente, articulado às outras instâncias sociais, é atravessado por diferentes discursos, revela e reproduz as doutrinas pedagógicas, políticas, religiosas, jurídicas e as mais diferentes produções culturais da sociedade. De certo modo, quando se enfatiza a escola como uma instância em que se produzem identidades sociais, está-se colocando o foco sobre processos e mecanismos de homogeneização, de uniformização e de nivelamento. Assim, as/os professoras/es devem estar atentas/ os para as práticas rotineiras e comuns, nas quais os sujeitos se envolvem, a fim de questionar e desconfiar daquilo que é tomado como natural, ainda que seja socialmente construído.

Currículos, materiais didáticos e as diversas linguagens dentro ou fora da escola são constituídos e constituintes de múltiplas diferenças e desigualdades. Segundo Silva (1999, p. 150), "o currículo é lugar, espaço, território. O currículo é relação de poder. O currículo é trajetória, viagem, percurso. O currículo é autobiografia, nossa vida, curriculum vitae: no currículo se forja nossa identidade. O currículo é texto, discurso, documento. O currículo é documento de identidade".

Dessa forma, então, seria importante e interessante tentar olhar para dentro da escola e do currículo e ver que histórias estão sendo produzidas e reforçadas sobre sexismo e preconceito, assim como as mais diferentes formas de exclusão. Podemos perceber também que, já no maternal ou no jardim de infância, as diferenças entre os gêneros já começam a ser demarcadas. Brinquedos e atividades 'apropriadas' a cada sexo já começam a estar presentes nas atividades que separam meninos e meninas, caracterizando uma clara distinção entre brinquedos de meninos e brinquedos de meninas. Por exemplo, brincadeiras e atividades físicas na escola consideradas de meninos caracterizam-se pela 
menção ao esporte, à agressividade, ao uso de movimentos mais amplos, à competitividade e à inteligência. Já para as meninas, destinam-se, geralmente, atividades mais calmas, com um apelo ao doméstico e à maternidade. Brincadeiras com bonecas, casinhas, panelinhas, minicozinhas que imitam uma cozinha de verdade e outros brinquedos que simulam o mundo privado e do cuidado com o outro também acabam por construir meninas dedicadas ao lar e à família. Esses aparatos funcionam não apenas como diversão, mas incentivam meninas para que permaneçam ligadas ao mundo doméstico e a tudo que o representa. Os tipos de jogos, de brincadeiras que professores/as oportunizam as/aos alunas/os e os espaços que são permitidos a meninas e meninos são alguns elementos que vão constituindo os indivíduos. Já os manuais escolares e os livros didáticos veiculam conteúdos essencialmente sexistas e em muitos aspectos já ultrapassados da realidade. Dessa forma, levando-se em conta que as escolas e os/as professores/as apoiam-se sobre os livros didáticos, isso é extremamente preocupante, na medida em que transmitem a imagem da mulher como incapaz e inferior ao homem, assim como tantos outros estereótipos.

Os livros didáticos, por meio da ideologia, também delimitam e instituem quais carreiras são 'adequadas' para as mulheres. O problema da transmissão dessas ideologias, por meio dos livros didáticos, é que numa fase compreendida entre as quatro primeiras séries do Ensino Fundamental, nas quais as crianças se encontram na faixa dos 7 aos 10 anos de idade, a postura crítica, a estabilidade e a maturidade ainda são duvidosas, podendo então, desse modo, condicionar o destino profissional, pessoal e social de meninos e meninas.

Outro aspecto a considerar - aqui o último - é a linguagem, que segundo Louro (1997) pode ser considerada como o campo mais eficaz e persistente para instituir relações, posições e fixar diferenças. Tanto a expressão oral e escrita, o silêncio, as regras e os livros didáticos são capazes de pontuar seu sexismo, racismo, homofobia, etnocentrismo, etc.

Dentre os múltiplos espaços e as muitas instâncias em que se pode observar a instituição das distinções e das desigualdades, 
a linguagem é, seguramente, o campo mais eficaz e persistente tanto porque ela atravessa e constitui a maioria de nossas práticas, como porque ela nos parece, quase sempre, muito 'natural'. (...) a linguagem não apenas expressa relações, poderes, lugares; ela os institui; ela não apenas veicula, mas produz e pretende fixar diferenças (LOURO, 1997, p. 65).

A autora também diz que, assim como a escola afirma e estimula a separação entre meninos e meninas, ela também é o palco para criação de situações que podem significar o cruzamento de fronteiras ${ }^{2}$ ou limites entre os gêneros, o qual pode produzir tanto o fortalecimento quanto a superação da diferença.

\section{Sexualidade e educação}

A sexualidade parece sempre ter ficado fora da escola. Essa é uma impressão que temos quando observamos as escolas e até mesmo os cursos de formação docente. O pior é que nem nos damos conta. Chegamos a pensar até mesmo que nossos professores e nossas professoras são seres de outro mundo, assexuados, como se tivessem apenas uma mente, como se todas as pessoas que trabalham na escola e com a educação fossem descorporificadas.

Por outro lado, a história da Educação nos mostra que não é bem assim que a escola funciona. Pelo contrário: a

$2 \mathrm{Na}$ análise cultural anglo-saxônica, o conceito de 'fronteira' (tradução de border) é utilizado para ressaltar o caráter instável, transitório e incerto da formação da identidade social e cultural. Num cenário de instabilidade identitária, as pessoas estão constantemente cruzando as fronteiras da identidade racial, sexual, nacional, étnica, etc. Num tom mais 'militante', a crítica cultural celebra o 'cruzamento de fronteiras' como um tom subversivo e transgressivo, por permitir confundir e borrar as fronteiras social e culturalmente estabelecidas. O 'cruzamento de fronteiras' está identificado com o pós-modernismo, o pós-estruturalismo e o multiculturalismo. Nas análises educacionais pós-estruturalistas, assinala tanto a possibilidade de transitar entre diferentes identidades, vistas como fluidas e instáveis, quanto entre diferentes formas de conhecimento cujas fronteiras são vistas como pouco nítidas e distintas. 
preocupação com a sexualidade e o corpo sempre foi central no engendramento dos processos, das estratégias e das práticas pedagógicas. O disciplinamento dos corpos e a normalização da sexualidade acompanharam historicamente a escolarização das mentes. Todos os processos de escolarização sempre estiveram ocupados em vigiar, modelar, corrigir e punir o corpo e a sexualidade de meninos e meninas.

Em Vigiar e punir (1987) de Michel Foucault, podemos perceber as inúmeras estratégias e técnicas inventadas para esquadrinhar os corpos, para conhecê-los e escolarizá-los, para produzir gestos e posturas considerados educados; construir cidadãos e cidadãs saudáveis, jovens responsáveis e respeitadores, adequados/as e dignos/as, endividados/as, cristãos/ãs. O olhar intensivo sobre a sexualidade das crianças, dos jovens e dos adultos ganha enorme atenção quando se volta para a sexualidade. A 'definição' sexual tem-se constituído como referência primeira sobre as pessoas. Lyanne Segal (apud LOURO, 2000) diz que:

\begin{abstract}
quando se chega a questões de identidade sexual, a 'construção social da identidade' deve inevitavelmente dar lugar aos imperativos da biologia e da natureza. Você pode aceitar que os comportamentos sociais que rotulam como 'masculinos' ou 'femininos' - isto é, questões de gênero - sejam socialmente definidos. Mas o que é socialmente construído ou culturalmente definido acerca da sexualidade?
\end{abstract}

Ainda que gênero e sexualidade se constituam em dimensões articuladas, é necessário diferenciá-las aqui. Estudiosas e estudiosos feministas têm se referido de maneiras diferentes falando de gênero e sexualidade. Sobre gênero, já foi falado anteriormente do entendimento que se tem trabalhado. Por outro lado, o conceito de sexualidade é utilizado para se referir às formas como os sujeitos vivem seus prazeres e desejos sexuais e nesse sentido, segundo Louro (2000), "as identidades sexuais estariam relacionadas aos diversos arranjos e parcerias que os sujeitos inventam e põem em prática para realizar seus jogos sexuais".

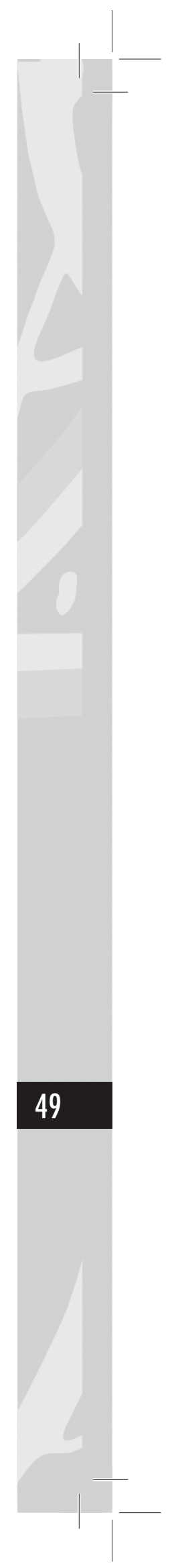




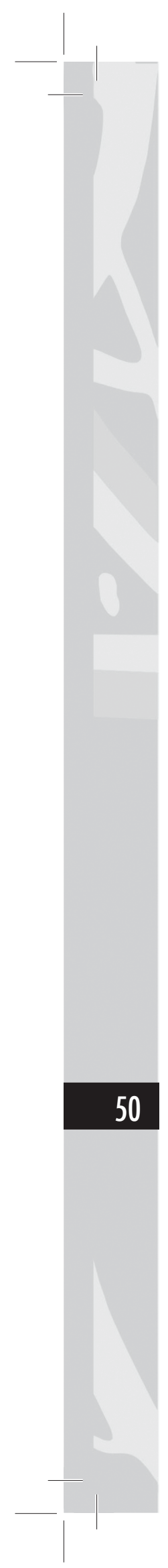

As formas de se viver a sexualidade são também influenciadas pelo meio cultural. Afirma-se que os sujeitos aprendem no interior da cultura determinados comportamentos e atitudes que naquele ambiente são considerados adequados para expressar seus impulsos e desejos sexuais. Embora se admita que existam diversos significados atribuídos às práticas sexuais, alguns estudiosos e estudiosas afirmam que a escolha do objeto sexual também se constrói socialmente. Segundo os/as estudiosos/as, não haveria qualquer predisposição intrínseca, biológica ou psicológica na base de uma identidade heterossexual, homossexual ou bissexual. A escolha do interesse erótico e sexual seria construída a partir de várias possibilidades de vivência da sexualidade, na dependência das histórias pessoais e subjetivas, dos significados culturalmente atribuídos a essas possibilidades. Nesse caso, afirma-se que o alvo do desejo sexual é socialmente produzido.

Linguagens, crenças, fantasias, códigos sociais, desejos inconscientes e atributos biológicos constituem a sexualidade em combinações e articulações complexas. Tal como o gênero, a sexualidade também precisa ser compreendida no âmbito da história e da cultura. Nessa ótica, as identidades sexuais deixam de ser concebidas como meros resultantes de 'imperativos biológicos' e passam a ser entendidas como constituídas nas relações sociais de poder, em complexas articulações e em múltiplas instâncias sociais. Sobre o contexto da cultura, experimentam as oscilações e os embates da cultura: algumas dessas identidades sexuais experimentam o privilégio, a legitimidade, a 'normalidade' e a autoridade. Já 'outras' identidades são representadas como desviantes, anormais e alternativas.

Enfim, as identidades consideradas 'normais' não precisam falar de si, anunciar sua escolha sexual, afinal é a 'regra', o comum, o 'natural', enquanto as 'outras' identidades quase sempre têm que ter algo a dizer sobre si, afinal pertencem ao diferente, ao exótico. São quase sempre representadas como sexualizadas e marcadas como patológicas.

É função então da escola desmistificar e trabalhar com as diferentes maneiras de se viver a sexualidade. A escola, seus professores e professoras precisam estar sempre atentos/as 
para evitar as armadilhas que são construídas para desprezar e posicionar como abjetos, obscenos e monstruosos aqueles/as estudantes que não seguem a 'norma'.

Com isso, é preciso que estejamos atentos/as para exorcizar qualquer tipo de preconceito e discriminação em relação à sexualidade e promover um total estranhamento em relação àquilo que é tomado como 'normal' e 'natural'.

\section{Por uma educação não-sexista}

Como podemos perceber, existem vários estudos que têm enfatizado as formas pelas quais se produzem diferenças, desigualdades e as diversas maneiras que se constroem identidades sociais, aqui falando, especificamente, das identidades de gênero e sexualidade na escola. Além disso, atributos que são sociais e históricos e "que são produzidos e fabricados de diferentes modos, por diferentes sujeitos, em diferentes momentos e sociedades, acabam por ser percebidos como universais e eternos" (LOURO, 1995, p. 174). Mas, como sabemos hoje, se as características vistas por muitos como inerentes à mulher ou ao homem são produzidas socialmente, sabemos também que são possíveis de transformação.

Louro (1997) propõe uma prática educativa não-sexista, recusando uma posição prescritiva e privilegiando a discussão de um modo novo de exercer uma ação transformadora no âmbito da educação. Assumindo o princípio de que as relações são sempre relações de poder e que o exercício do poder acontece em múltiplas direções, a autora discute uma nova configuração para a/o intelectual feminista que resulta de um conjunto de disposições mais sintonizadas numa perspectiva pós-estruturalista: disposição para observar e questionar os indícios de desigualdade e suas eventuais desestabilizações ou mudanças para estar atento/a, portanto, não apenas ao que se ajusta às representações dominantes, mas também ao que se apresenta como inesperado, como forma de transposição de fronteiras, como transgressão do instituído; disposição para o autoquestionamento para lidar com a provisoriedade e a transitoriedade; disposição para agir a partir das práticas cotidianas, rotineiras e comuns. Tais disposições 


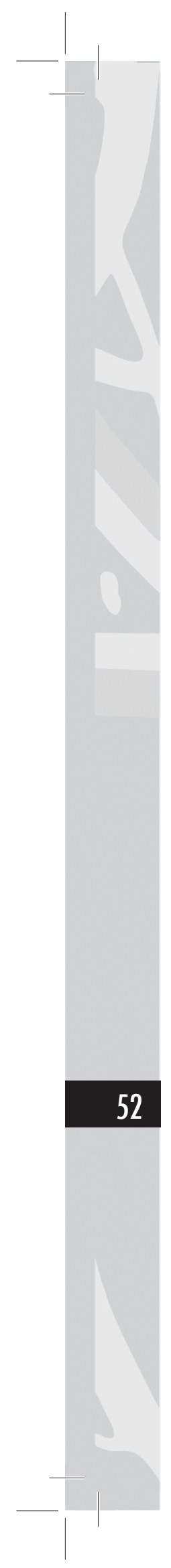

são construídas através da informação, do conhecimento, do desejo e do compromisso político. Elas produzem ações que, embora contingentes a cada situação particular, contribuem para atemorizar as fáceis certezas, para ensinar a crítica e a autocrítica, para abalar as hierarquias.

Discutindo ainda sobre o papel da educadora numa prática educativa não-sexista, Tomaz Tadeu da Silva (1996, p. 241) comenta as modificações do "papel da intelectual" num contexto pós-moderno e pós-estruturalista. Ele lembra que a "posição afastada, distanciada em relação ao mundo social e político", característica do Iluminismo, é, agora, "insustentável”; o mesmo acontece com o papel 'vanguardista' atribuído às/aos intelectuais das chamadas pedagogias críticas. Segundo Tomaz:

As noçães pós-estruturalistas de poder vão conferir à intelectual um papel bem mais modesto, muito menos universal e muito mais local, que se expressa na noção de 'intelectual especifica' de Foucault. Nessa perspectiva, a intelectual assume um papel muito mais simétrico em relação às outras participantes das lutas sociais nas quais está envolvida, no sentido de que seu saber, sua visão e seu discurso devem tanto ao interesse de poder quanto o de qualquer outra participante.

Também, sobre a pós-modernidade, Louro (1997, p. 123) afirma que, “(...) ao contrário daqueles/as que associam as perspectivas pós-modernas ao abandono das causas coletivas, ao incitamento ao relativismo e à fragmentação, desmobilizadores e apolíticos, acredito que podemos ler, nessas perspectivas, um movimento oposto: o revigoramento e ampliação do político".

Provavelmente a mudança dessa forma de abordar a educação e o gênero, numa outra perspectiva, implica mudanças, desconstruções e até mesmo perturbações extremamente significativas para qualquer um/a. Trata-se de compreender que a construção dos sujeitos, e especificamente dos gêneros, é um processo social e histórico e que a diferença, seja ela qual for, também é uma construção feita por relações de poder a partir 
de um determinado 'lugar' que se toma como a norma, o centro, o natural. Assim, muitas das práticas que foram apontadas aqui, embora com receio e medo, estão sendo modificadas. No entanto, é preciso estarmos atentos/as, pois, segundo a educadora e feminista Guacira Louro (1995, p. 180), "na escola algumas vezes são desenvolvidas transformações que servem apenas para revestir de novas formas um mesmo processo de desigualdade ou discriminação".

\section{Considerações finais}

Conforme a reflexão do texto, pode-se perceber que ainda existem profundas barreiras que separam homens e mulheres, particularmente no que diz respeito à educação. Não somente uma educação como instituição escolar, mas também que envolve muitos preconceitos que definem comportamentos, atitudes, saberes e gestos no processo social e histórico na formação de sujeitos masculinos e femininos, já que esses estão implicados nas mesmas relações sociais e históricas.

Como foi visto no item intitulado 'Fazendo gênero', hoje os preconceitos relativos à educação mais adequada para a mulher já não se manifestam de forma tão visível como no passado. A escola continua reproduzindo as diferenças e desigualdades sociais, mas atualmente de uma forma mais velada. Dessa forma, é possível admitir que a escola não apenas transmite conhecimentos, mas que ela fabrica sujeitos masculinos e femininos e produz suas identidades sociais. Se for possível reconhecer que essas desigualdades estão sendo produzidas e que a escola está intrinsecamente comprometida com a manutenção de uma sociedade dividida, fazendo isso cotidianamente, com participações e omissões; se acreditamos que a prática escolar é historicamente contingente e que é uma prática política, isto é, que se transforma e pode ser subvertida e, por fim, se não nos sentimos conformes com essas divisões sociais, então, certamente, encontramos não apenas justificativas para observar e analisar, mas especialmente para tentar ao menos interferir na continuidade dessas desigualdades. 


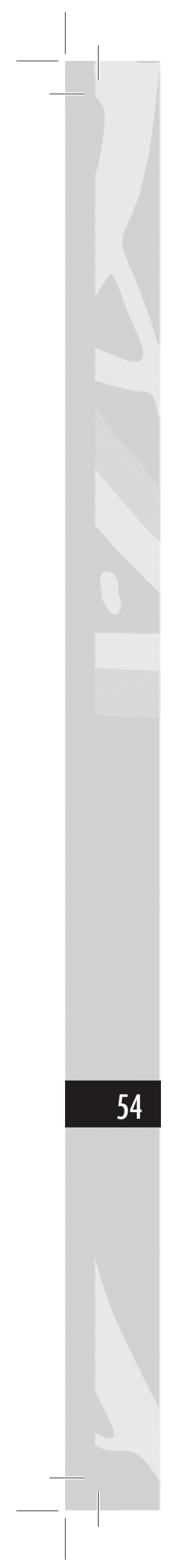

Dessa forma, busquei, através de estudos, pesquisa bibliográfica e reflexão uma forma de anunciar alguns estereótipos sobre o sexo feminino, especificamente no que tange a temática de gênero e sexualidade, aspectos que trago à discussão, uma vez que, historicamente, ainda existem dificuldades para lidar com as questões de preconceito e discriminação, devendo-se então estar atentos/as para os valores que são reforçados em qualquer situação do contexto escolar e também em qualquer momento em que podemos estar passando por processos de subjetivação.

Através de um olhar crítico sobre o currículo, deve-se promover um processo em que haja transformação em relação à pluralidade cultural de gênero e sexualidade. Através de autoconhecimento e do desenvolvimento de sua consciência profissional e crítica, o/a educador/a deverá saber por que está ali, por que ensinar e o que ensinar, uma vez que só um sujeito crítico e consciente politicamente tem condições de modificar a realidade. Assim, quando se põem em discussão as questões de gênero e sexualidade, pode-se também acoplar o tema da diferença, começando por reconhecer a existência de padrões de socialização baseados em estereótipos sexuais que determinam o lugar da menina e do menino na escola e, por extensão, na sociedade. Esses estereótipos são tão bem construídos e manipulados que são absorvidos por todas as pessoas como algo 'natural' e 'normal'.

Talvez não seja possível modificar as concepções e valores da sociedade como um todo, mas, no que diz respeito à educação, é tarefa de todos/as nós educadores/as refletirmos acerca da função que ocupamos na formação das crianças, adolescentes, jovens e adultos. Essa atitude de análise crítica dos currículos acarretaria a construção de autonomia por parte das/os estudantes, ou seja, estaríamos no processo de formação de sujeitos críticos. Nesse sentido, cabe aos/as educadores/as deparar o/a aluno/a com situações em que ele/ela mesmo/a tem que resolver, com momentos em que tem que refletir, criticando, posicionando-se, envolvendo-se e decidindo.

Fazer educação potencializando os vários tipos de vida que encontramos pela Terra, preservando os diferentes 
desejos, é o que interessa. Dessa forma, é possível afirmar que o/a educador/a torna-se peça indispensável para o despertar do senso crítico e do pensar dos/as alunos/as, para uma sociedade não-preconceituosa, machista e hipócrita como tem sido a nossa.

Uma educação não fascista em permanente luta para aumentar a potência de agir, pensar, viver e amar de cada vida. Inspira ao/a educador/a tal prática?

\section{REFERÊNCIAS}

AZEVEDO, J. C.; SILVA, L. H. (Org.) Reestruturação curricular: teoria e prática no cotidiano da escola. Rio de Janeiro: Vozes, 1995. p. 172-182.

Gênero, sexualidade e educação: uma perspectiva pósestruturalista. Rio de Janeiro: Vozes, 1997.

O corpo educado: pedagogias da sexualidade. Belo Horizonte: Autêntica, 2000.

COSTA, Marisa V. (Org.) O currículo nos limiares do contemporâneo. 3. ed. Rio de Janeiro: DP\&A, 2001.

FARIA, A. L. F. G. Ideologia no livro didático. São Paulo: Cortez, 1984.

FOUCAULT, Michel. História da sexualidade: o uso dos prazeres. Rio de Janeiro: Graal, 1984.

FREITAG, B.; COSTA, V. F. O livro didático em questão. São Paulo: Cortez, 1989.

LOURO, Guacira L. Prendas e Antiprendas: uma escola de mulheres. Porto Alegre: Ed. UFRGS, 1987. 
Educação e gênero: a escola e a produção do feminino e do masculino. In:

MOLINA, Olga. Quem engana quem? Professor versus Livro Didático. São Paulo: Summus, 1980.

MEYER, Dagmar E. Escola, currículo e produção de diferenças e desigualdades de gênero. In: SCHOLZE, Lia. (Org.). Gênero, memória, docência. Porto Alegre: Prefeitura Municipal de Porto Alegre, 2001.

RIBEIRO, Marcos. Menino brinca de boneca? Conversando sobre o que é ser menino e menina. Rio de Janeiro: Salamandra Consultoria Editorial, 1990.

SCOTT, Joan. Gênero: uma categoria útil de análise histórica. Educação e realidade. Porto Alegre, v. 16, n. 2, p. 5-19, jul.-dez. 1990.

SILVA, Tomaz T. da. Documentos de Identidade: uma introdução às teorias do currículo. Belo Horizonte: Autêntica, 1999.

(Org.); HALL, S.; WODWARD, K. Identidade e diferença: a perspectiva dos estudos culturais. Petrópolis: Vozes, 2000.

Teoria cultural e educação: um vocabulário crítico. Belo Horizonte: Autêntica, 2000.

Tradução Guacira L. Louro. A identidade cultural na pósmodernidade. 4. ed. Rio de Janeiro: DP\&A, 2000. 